\title{
Proton-electron precipitation effects on the electron production and density above EISCAT (Tromsø) and ESR
}

\author{
J. Lilensten ${ }^{1}$ and M. Galand ${ }^{2}$ \\ ${ }^{1}$ SGEP-CEPHAG, BP 46, 38402 St Martin d'Hres cedex, France \\ ${ }^{2} \mathrm{HAO} / \mathrm{NCAR}$, PO Box 3000, Bouler, CO 80307, USA
}

Received: 13 November 1997 / Revised: 5 June 1998 / Accepted: 8 June 1998

\begin{abstract}
The suprathermal particles, electrons and protons, coming from the Sun and precipitating into the high-latitude atmosphere are an energy source for the Earth's ionosphere. They interact with the ambient thermal gas through inelastic and elastic collisions. Most of the physical quantities perturbed by the precipitation, such as the electron production rate, may be evaluated by solving the stationary Boltzmann transport equation, which yields the particle fluxes as a function of altitude, energy, and pitch angle. This equation has been solved for the three different suprathermal species (electrons, protons and hydrogen atoms). We first compare the results of our theoretical code to a coordinated DMSP/EISCAT experiment, and to another approach. Then, we show the effects that pure proton precipitation may have on the ionosphere, through primary and secondary ionization. Finally, we compare the effects of proton precipitation and electron precipitation in some selected cases above EISCAT (Tromsø) and ESR.
\end{abstract}

Key words. Ionosphere (auroral ionosphere; ionosphere-magnetosphere interactions; particle precipitation).

\section{Introduction}

Until recently, theoretical analysis of the aurora has been largely limited to the study of electron precipitation. However, proton precipitation has been detected from ground-based observations as early as the 1940s (Vegard, 1948), and satellite or rocket measurements have corroborated their presence (Sharp et al., 1967,

Correspondence to: $\mathrm{J}$. Lilensten
1969; McNeal and Birely, 1973 and references therein). A statistical study (Hardy et al., 1989) indicated that the integral energy flux of protons can equal or exceed that for the electrons for some latitudes and local times on the eveningside of the oval, and is a significant fraction of the electron integral energy flux for much of the oval.

In response to these measurements indicating that protons are able to have a major influence on the polar ionosphere, proton transport theory has received increased attention. To describe the energy loss undergone by the precipitating protons, Edgar et al. (1973, 1975) assumed that the particles were slowed down continuously in the medium. Introducing an energy deposition function and setting a value for the energy loss per electron-ion pair, Rees (1982) determined several physical quantities, such as electron production or emission rates. Jasperse and Basu (1982) and Basu et al. (1990, 1993) opened a new way of investigation by solving the transport equations. Comparisons with incoherent scatter radar data showed that the electron density, an integrated quantity estimated from transport equations, agreed well with observations (Basu et al., 1987; Senior et al., 1987). Proton transport was also simulated by a Monte Carlo method and a collision-by-collision degradation scheme (Kozelov and Ivanov 1992, 1994; Kozelov, 1993). Recently Decker et al. (1996) performed a comparison of three of these methods, a Monte Carlo simulation (Kozelov and Ivanov, 1992), a discrete energy loss solution to the linear transport equations (Basu et al., 1993), and a continuous slowing down approximation (Decker et al., 1996). The agreement of the three models is excellent except at the lowest altitudes, largely below the region where the bulk of energy deposition and ionization takes place. Finally, Galand et al. (1997) proposed a new method to solve the coupled $\mathrm{H} / \mathrm{H}^{+}$transport equations that allowed to include angular redistributions. Their solution is based on the introduction of dissipative forces to describe energy redistribution during collisions. Their model has been validated through comparison with the model of 
Basu et al. (1993), whose results are presented in Strickland et al. (1993) (comparison of the energy spectra of the proton and hydrogen fluxes as well as the electron production rates), through the evaluation of energy conservation, and finally through a successful comparison with the Proton I rocket data. In a second paper, Galand et al. (1998) studied the influence on $\mathrm{H}$ emissions of the angular redistribution due to the magnetic mirroring effect and to collisions.

Concerning electron precipitation effects, many different approaches have been taken. Here too, a range calculation (Rees, 1963; Vallance Jones, 1974) can, to some extent, replace a rigorous solution of a transport equation. For this approach, an energy deposition function is scaled to real atmospheric densities (Grün, 1957). However, this approach cannot give information about the angular redistribution of precipitating electrons due to elastic scattering: the basic assumption is the one of a continuous energy loss during collisions. Berger et al. (1970) adopted a Monte Carlo code and presented results on the spreading of an auroral arc perpendicular to the ambient geomagnetic field. Photoelectron transport and thermalization were solved by Mantas (1975) with an iteration method. Two-stream solutions of the transport equations were obtained by Nagy and Banks (1970), Banks et al. (1974), Stamnes (1980, 1981), Richards and Torr (1985), Link et al. (1988) and others. Jasperse (1976) applied a diffusion approximation to solve the photoelectron transport equation and presented an analytic approach to the auroral electron transport problem (Jasperse and Strickland, 1981). Strickland et al. (1976, 1983, 1989) presented a solution to the electron transport equation that solved the pitch angle distribution of the penetrating stream of electrons. Lummerzheim et al. (1989) solved the electron transport equation by separating the energy degradation from the transport and scattering equation, and used a discrete ordinate method. This last approach has been discussed in Lummerzheim and Lilensten (1994), and validated through comparisons with laboratory experiments and auroral observations. Later, it has been widely used, for example to understand the physics of arcs (Lanchester et al., 1994) and, combined with a chemistry and dynamics code, to describe the high latitude conductances (Lilensten et al., 1996) or the effect of substorms on ion composition (Blelly et al. 1996; Lathuillere et al., 1997).

The next step has been to couple the codes describing dual proton/electron precipitation effects on the ionosphere. This was achieved for the first time by Basu et al. (1993). These authors use the approach of Basu et al. (1990) to describe the proton transport and of Strickland et al. (1976) for the electron transport. Strickland et al. (1993) show the results of this coupled code on some ionization profiles and emission lines. Anderson et al. (1997) use this code to compare with a spacecraft/ radar experiment which is described later.

The present study shows a second approach to coupled proton/electron transport. The proton scheme is that of Galand et al. (1997), while the electron scheme is that of Lummerzheim and Lilensten (1994). In Sect. 2, we compare this code to the Anderson experiment. In Sect. 3, we present the contribution of electrons and protons on the electron density during this experiment; then we show the effects of pure proton precipitation on the auroral ionosphere. Finally, in Sect. 4, we discuss the effects of combined precipitations on the electron production and electron density above EISCAT (Tromsø) and ESR.

\section{Comparison with experiment}

Recently, Anderson and co-authors undertook several experimental campaigns to obtain simultaneous radar and satellite measurements that would provide insight into the temporal and spatial morphology of the energetic particle precipitation (Anderson et al., 1997). At the top of the ionosphere, the DMSP satellite measured the precipitated fluxes of electrons and ions. The precipitating energetic particle spectrometer (SSJ/4) aboard the DMSP spacecraft measures electrons and ions in 20 energy channels ranging from $30 \mathrm{eV}$ to $31.3 \mathrm{keV}$ every second. The sensors are oriented such that their look direction is within a few degrees of local vertical, so that in the auroral zone they are measuring precipitating particles with pitch angles within the loss cone. A complete description of this sensor can be found in Hardy et al. (1984).

The EISCAT radar was operated using the Finnish PULSE experiment, which provided both power profile and lag profile information above a height of $75 \mathrm{~km}$, as well as conventionally gated autocorrelation functions above $105 \mathrm{~km}$. It has the unique advantage to obtain power profiles at a time resolution of $0.2 \mathrm{~s}$, using a timeslicing approach. Details on this experimental mode may be found in Lanchester et al. $(1994,1996)$ and in Turunen et al. (1994).

On December 5, 1994, the DMSP F10 satellite measured the precipitation in very close conjunction with the EISCAT radar at Tromsø, operating in the PULSE mode: the spacecraft crossed the invariant latitude of the radar $0.3^{\circ}$ away in longitude (less than $12 \mathrm{~km}$ when projected to $100 \mathrm{~km}$ altitude). Amongst the diverse conjunctions of this campaign, that one is the only case with a significant amount of energy carried by the protons (Fig. 1). The proton flux fits well to a Maxwellian with a characteristic energy of $7.6 \mathrm{keV}$, and a total energy flux of $1.38 \mathrm{erg} \cdot \mathrm{cm}^{-2} \cdot \mathrm{s}^{-1}$. This downward flux is assumed isotropic. The electron flux is a Maxwellian with a characteristic energy of $1 \mathrm{keV}$ and a total energy flux of $0.37 \mathrm{erg} \cdot \mathrm{cm}^{-2} \cdot \mathrm{s}^{-1}$. It also features a high energy tail adding $0.26 \mathrm{erg} \cdot \mathrm{cm}^{-2} \cdot \mathrm{s}^{-1}$. This high energy tail is measured before and after the conjunction with the radar. During the overpass of EISCAT, Anderson et al. (1997) estimate that the amplitude of this tail is just below the threshold of the instrument. The minimum and maximum of the electron densities measured by the radar are plotted in Fig. 2: all the densities between 19:10:57 and 19:11:39 UT fall within the two thin solid lines. The dashed line shows the electron density computed by Anderson et al. (1997). 


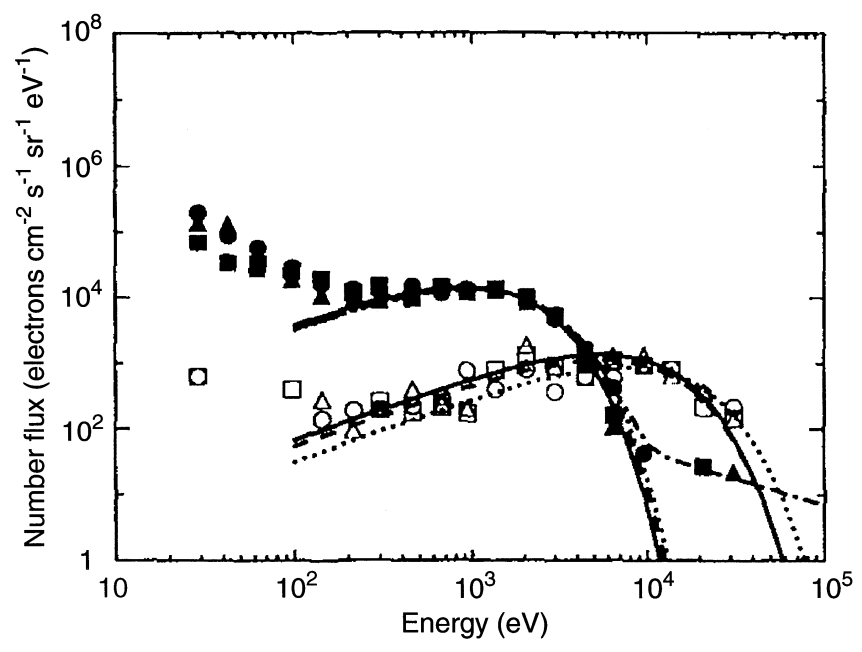

Fig. 1. Particle spectra near the time of the conjunction on December 5, 1994. Triangles show measurements at 19:11:36 UT. Circles are for 19:11:37 UT and squares for 19:11:38 UT. Open symbols show the ion precipitation and solid symbols the electrons. A Maxwellian fit has been performed for both particle spectra, and the electron spectrum exhibits a high energy tail (Anderson et al., 1997)

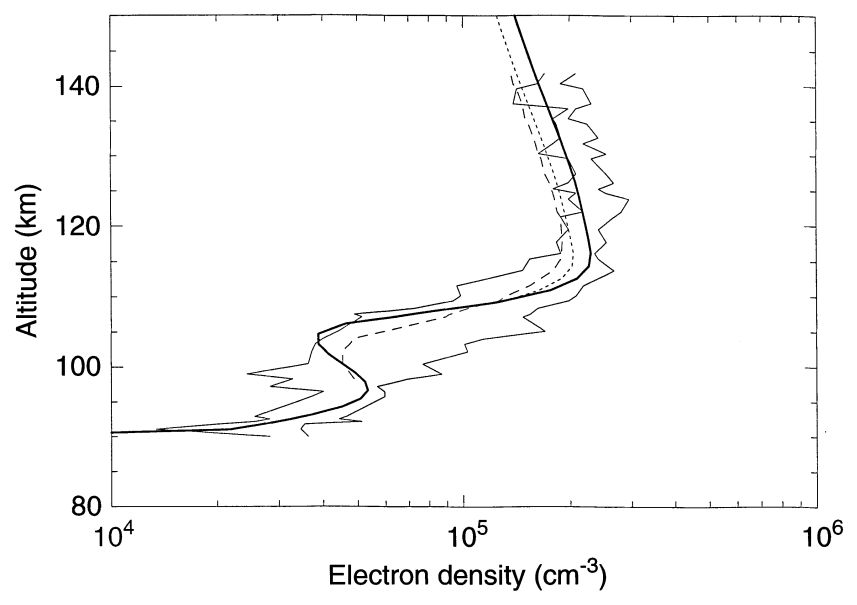

Fig. 2. The two thin solid lines show the maximum and minimum electron densities measured by the EISCAT radar above Tromsø on December 5, 1994, during the overpass of the DMSP spacecraft. The dashed line is from the computation of the electron density by Anderson et al. (1997). The dotted line and the thick solid line are from our present computation with an attenuation factor for spreading of 0.75 and 1 respectively

The dotted line represents the electron density computed from the present approach. No angular redistribution of the proton beam is considered here. In the energy range involved, forward scattering of the proton precipitation constitutes a relatively good approximation. The neutral model is given by MSIS90 (Hedin, 1991) for the geophysical conditions of the day of observations. The calculation of electron density from electron production (the direct output of a transport code) uses a recombination coefficient (Oran et al., 1981) valid from the low $\mathrm{E}$ region up to approximately $180 \mathrm{~km}$. Moreover, the computation is made under the usual assumption (also made in Anderson et al., 1997) that the proton beam experiences an attenuation at the center due to spreading induced by the first neutral path of the energetic particles; the attenuation coefficient applied to the incident flux is as 0.75 (Jasperse and Basu, 1982). There is a very good overall agreement between the present computation and the Anderson et al. (1997) computation at altitudes above $103 \mathrm{~km}$. Both computations are slightly smaller than the measurements above $120 \mathrm{~km}$. The main discrepancy between the two codes appears between 105 and $100 \mathrm{~km}$, but both results are within the maximum and minimum density profiles. The differences between the two codes may come from the cross-section sets or from the mathematical schemes. However, considering all the uncertainties in the measurements and internal parameters (neutral atmosphere, cross sections, experimental error bars, use of a recombination coefficient), this comparison proves that the two codes give very close results.

The thick solid line represents the electron density computed from the present approach with an attenuation coefficient of 1 , that is no spreading is considered. It shows a much better agreement with the data at all altitudes, especially above $110 \mathrm{~km}$. This suggests that there is no significant spreading. This could be explained by the optical observations showing a diffuse aurora during the experiment (Anderson et al., 1997) as well as the homogeneity of the particle flux over at least $2 \mathrm{~s}$, which represents approximately $16 \mathrm{~km}$ (see Fig. 1): the incident proton beam seems to have a certain extend over latitude and longitude. One can consider that, except at the borders of the aurora, there is an isotropy of the fluxes transverse to the magnetic field: when a proton is neutralized and leaves the center of the beam at a given altitude, another hydrogen atom comes from nearby and statistically replaces the former. Of course, one needs to be very careful and not draw definite conclusions from this single comparison.

\section{Effect of pure proton precipitation above EISCAT}

Figure 3 shows the effects of the electrons (dashed line) and protons (thin solid line) for the same coordinated experiment. The former creates the low $\mathrm{E}$ region with a peak at $95 \mathrm{~km}$. This production is due to the highenergy tail. The effect of the $1 \mathrm{keV}$ Maxwellian is to create some density (about $6.5 \times 10^{4} \mathrm{~cm}^{-3}$ ) at $120 \mathrm{~km}$. The protons are responsible for most of the density above $105 \mathrm{~km}$ : twice, even up to three times, as much as that due to the electron precipitation. Such a comparison emphasizes the key role the proton precipitation can play in the ionosphere.

We now study the effect of precipitation over EISCAT for the same geophysical conditions as the day of the DMSP/EISCAT coordination experiment above. We use Maxwellian-shaped input fluxes. The energy flux of the different inputs is $1 \mathrm{erg} \cdot \mathrm{cm}^{-2} \cdot \mathrm{s}^{-1}$. No angular redistribution in proton beam is considered and spreading is neglected. Figure 4 shows the primary electron production due to the proton precipitation 


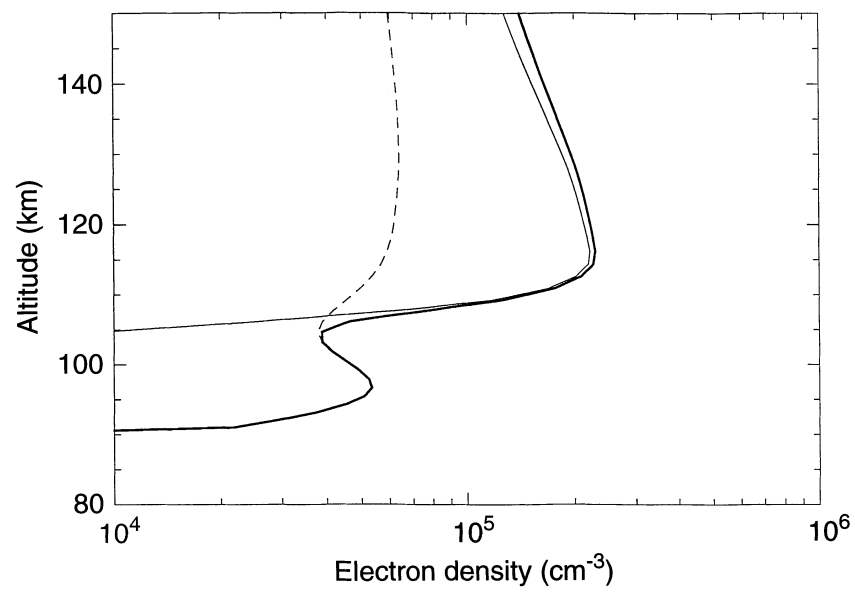

Fig. 3. The bold line is the present computation of the electron density from the coupled electron/proton transport equations, as in Fig. 1. The thin solid line is the electron density when the only source is the protons, and the dashed line takes only the electron precipitation into account.

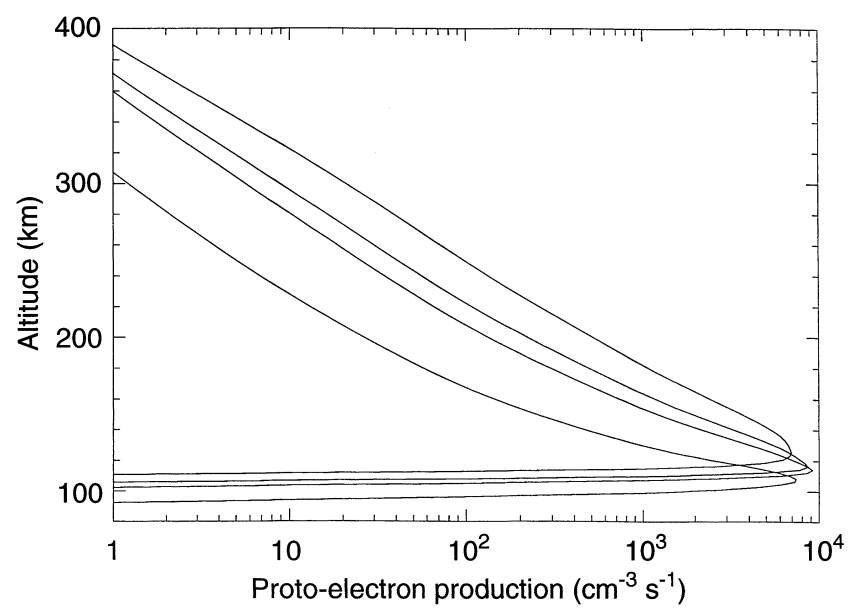

Fig. 4. Proto-electron production rate by energetic protons versus altitude. Above the peak production, from top to bottom, one finds the production for a $1 \mathrm{keV}, 5 \mathrm{keV}, 10 \mathrm{keV}$ and $50 \mathrm{keV}$ Maxwellian input proton spectrum

impacting the atmosphere, for four input characteristic energies: $1 \mathrm{keV}, 5 \mathrm{keV}, 10 \mathrm{keV}$ and $50 \mathrm{keV}$. The primary electrons created are called "proto-electrons" in analogy with "photo-electrons", which are primaries due to solar photoionization. The production peaks at low altitudes: from $125 \mathrm{~km}$ for the $1 \mathrm{keV}$ input flux to $108 \mathrm{~km}$ with the $50 \mathrm{keV}$ input flux. The energy distributions of the proto-electron source functions are shown in Fig. 5, for the four input energies described already, and at four different altitudes $(160 \mathrm{~km}, 131 \mathrm{~km}, 111 \mathrm{~km}$ and $105 \mathrm{~km})$. The particles have energies ranging typically below $100 \mathrm{eV}$. Such energies, above the various ionization thresholds, of the order of $12 \mathrm{eV}$, are sufficiently high to allow the primary proto-electrons to ionize and create a secondary electron flux. This secondary production is computed from the electron transport code, and is shown in Fig. 6. Since the $50 \mathrm{keV}$ input protons produce higher energy proto-electrons than the lower energy protons, it is not surprising that the secondary electron production amplitude follows the input energy. The ratio of secondary production over primary proto-electron production is approximately constant at any altitude (see Fig. 7). With the $50 \mathrm{keV}$ input proton flux, it is about $30 \%$, while it decreases to only $0.1 \%$ with the $1 \mathrm{keV}$ input proton flux. This clearly shows that the proton precipitation has relatively little effect on the secondary electron production. The decrease of this proto-electron efficiency with decreasing characteristic energy of the Maxwellian precipitating proton flux is nearly linear, with a slope of $0.006 \mathrm{keV}^{-1}$. The main interest of this result is that the primary protoelectron production due to pure proton precipitation may be described with an energy deposition function, setting a value for the energy loss per electron-ion pair (Rees, 1982). This approach does not take the secondary production into account, which becomes possible through the proto-electron efficiency discussed already. Namely:

secondary production

$$
=\text { primary production } \times 0.006 \mathrm{E}_{\text {char }}
$$

where $E_{\text {char }}$ represents the characteristic energy of the precipitating Maxwellian proton flux in $\mathrm{keV}$.

It should be noted that this efficiency is much smaller than the photo-electron equivalent (Richards and Torr, 1988; Lilensten et al., 1989). Indeed, the photoelectron efficiency is nearly constant (about $30 \%$ ) in the $\mathrm{F}$ region, but reaches several hundred percent in the E region, allowing the secondary production to become larger than the primary production. Finally, we would like to emphasize the fact that the photoelectron efficiency is a function of the altitude, while the protoelectron efficiency is a constant multiplicative factor of the characteristic energy.

\section{Proton-electron precipitation above EISCAT (Tromsø) and ESR}

After having shown the effect of pure proton precipitation in the ionosphere, it is important to study whether this effect is comparable, larger, smaller or negligible with respect to the electron precipitation effect. This must be studied in any part of the high-latitude ionosphere, but some regions are of particular importance: the auroral oval, and its edges, the polar cap.

The difficulty of such a study has been very well summarized by Strickland and co-authors (1993). They state that "a difficulty one faces here is the selection of the two characteristic energies and total energy fluxes for the incident electron and $\mathrm{H}^{+}$distributions". These authors pick one incident $\mathrm{H}^{+}$spectrum and show the variations in the resulting electron density profile as incident electrons are added. We choose here to proceed differently: we want to study the statistical effect of mean electron and proton precipitations above EISCAT (Tromsø) and ESR (Svalbard). EISCAT makes measurements in the equatorward edge and inside the 


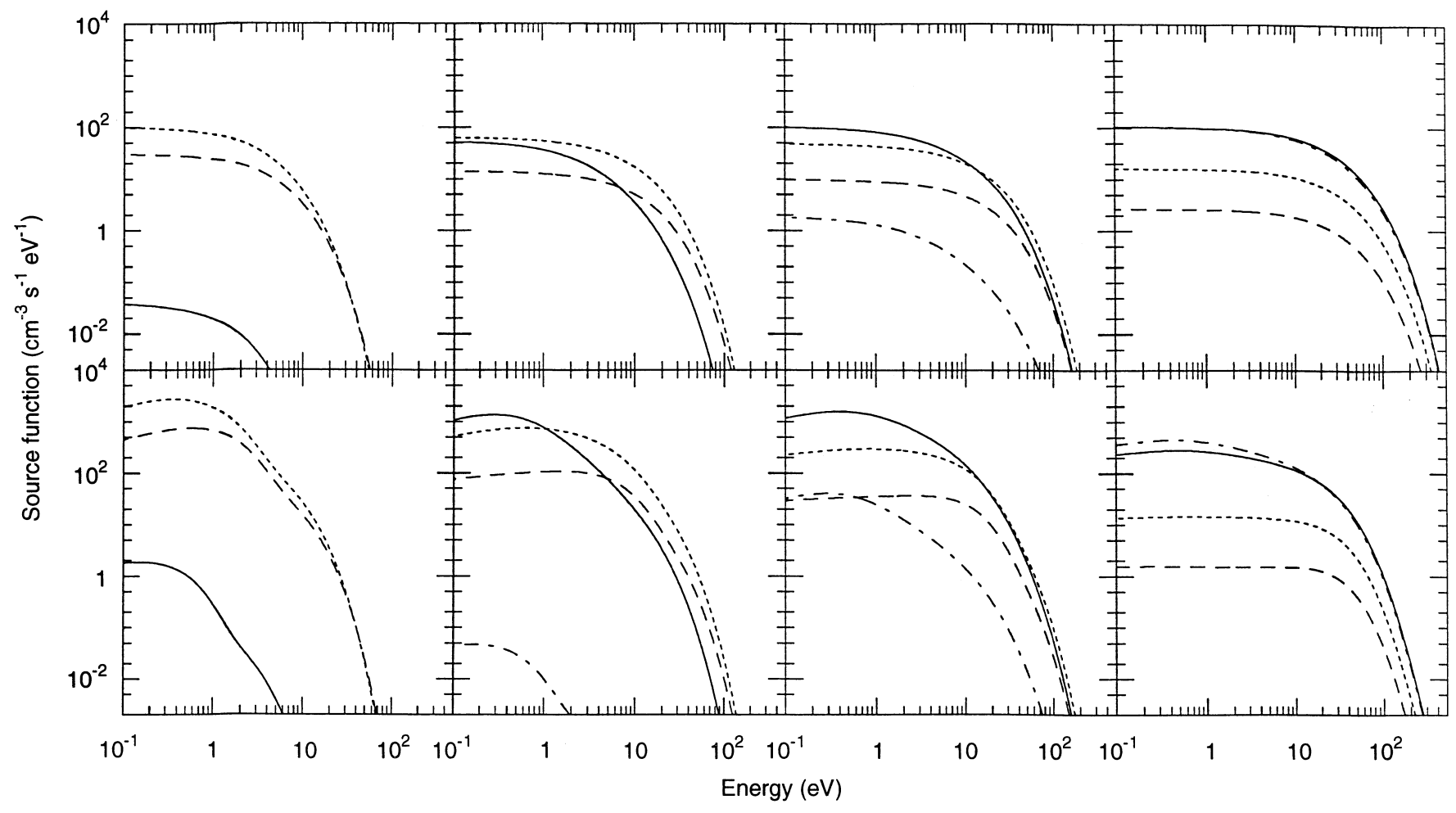

Fig. 5. The abscissa is the energy of the proto-electrons in eV. The ordinate is the proto-electron source function. In the four upper panels, the source functions are related to interactions between protons and ambient neutrals; in the four lower panels, they are related to collisions between $\mathrm{H}$ atoms and ambient neutrals. From left to right are the results due to the $1 \mathrm{keV}, 5 \mathrm{keV}, 10 \mathrm{keV}$ and finally $50 \mathrm{keV}$ input Maxwellian proton fluxes. The dashed lines are the source functions at $160 \mathrm{~km}$ height; the dotted lines, at $131 \mathrm{~km}$; the solid lines at $111 \mathrm{~km}$ and the dash/dotted lines at $105 \mathrm{~km}$

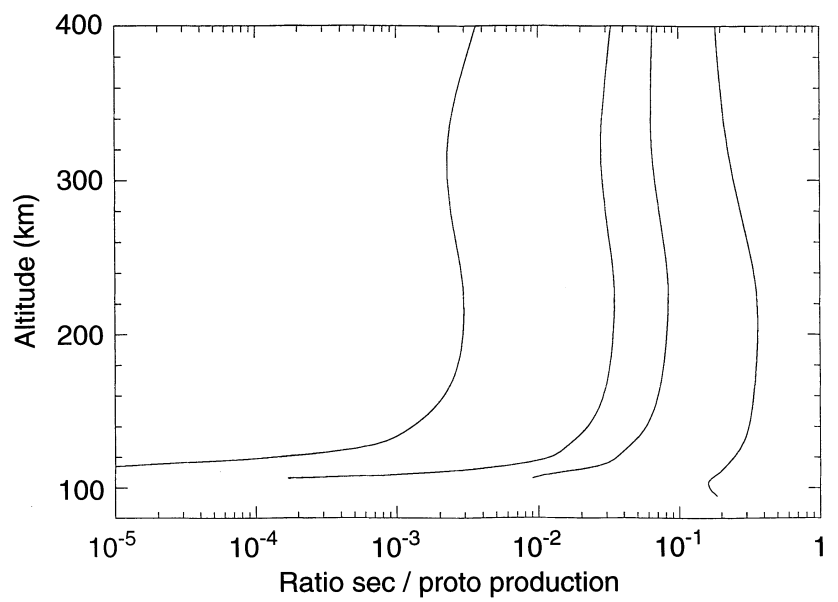

Fig. 7. The ratio between secondary electrons and primary protoelectrons versus height for four energies of input Maxwellian protons: $1 \mathrm{keV}$ (left), $5 \mathrm{keV}, 10 \mathrm{keV}$ and $50 \mathrm{keV}$ (right)

far as the electrons are concerned, they distinguish two populations. The first, with mean energies larger than $600 \mathrm{eV}$, is mostly found on the morningside of the auroral oval, and for a given $\mathrm{Kp}$, have one maximum after midnight and before noon. It constitutes the main contribution to the energy flux. The second population, with energies smaller than $600 \mathrm{eV}$, are concentrated between the pole and the poleward border of the hot 
electron zone. It constitutes the main contribution to the particle number flux. Regarding the ion precipitation, they find that "for a given $K p$ value the higher levels of integral energy flux occur in C-shaped regions symmetric about a meridian running from prenoon to premidnight, with a maximum premidnight"

The comparison of electron and ion precipitations shows that the average integral number flux for the ions is one to two orders of magnitude lower than that for the electrons at all latitudes, magnetic local times and magnetic activities. However the integral ion energy flux, on the eveningside of the oval, may exceed that for the electrons, near the equatorward edge of the auroral region.

The properties of the average fluxes are illustrated in Fig. 8. To compute the characteristic energy from the energy and particle fluxes, we made the assumption of Maxwellian fluxes, although Hardy et al. (1985, 1989) state that "these spectra are not Maxwellian, that is, not straight lines, but instead have continuously changing slopes". Therefore, the use of these Maxwellian spectra in our codes will certainly introduce some uncertainties in the results. However, this statistical study is the most complete one to date, and we must make some assumptions about the spectral shape for our modeling. Some authors found that the amplitudes given by Hardy et al. $(1985,1989)$ are underestimated (Senior, 1991), but Lilensten et al. (1996) found that the Hardy statistics with an assumed Maxwellian spectrum shape could explain the conductivities observed by EISCAT at low solar zenith angles.

Figures 9 and 10 show respectively the electron production and electron density above EISCAT (Tromsø) and ESR. On the left side, we use only the electron precipitation. The results depend not only on the precipitation, but also on the neutral atmosphere. Above EISCAT, the trough in the energy flux of the precipitation between 9 and 15 UT is fairly visible in both the electron production and electron density. Adding the proton flux leads to filling this part of the ionosphere from about $10^{4}$ to about $5 \times 10^{4}$ electrons $\cdot \mathrm{cm}^{-3}$. At noon, the major effect of the addition of protons is to reduce the height of the density maximum, from $160 \mathrm{~km}$ to about $120 \mathrm{~km}$. This is of course due to the peak in the characteristic energy of the protons.

The effect above ESR is also quite spectacular. Indeed, the electrons create almost no density around 10 UT. This is due to the decrease in the energy flux in this time period, to a very small characteristic energy creating the ionization at higher altitudes, and to the neutral atmosphere. Adding the protons enlarges the

EISCAT (Tromso)

ESR

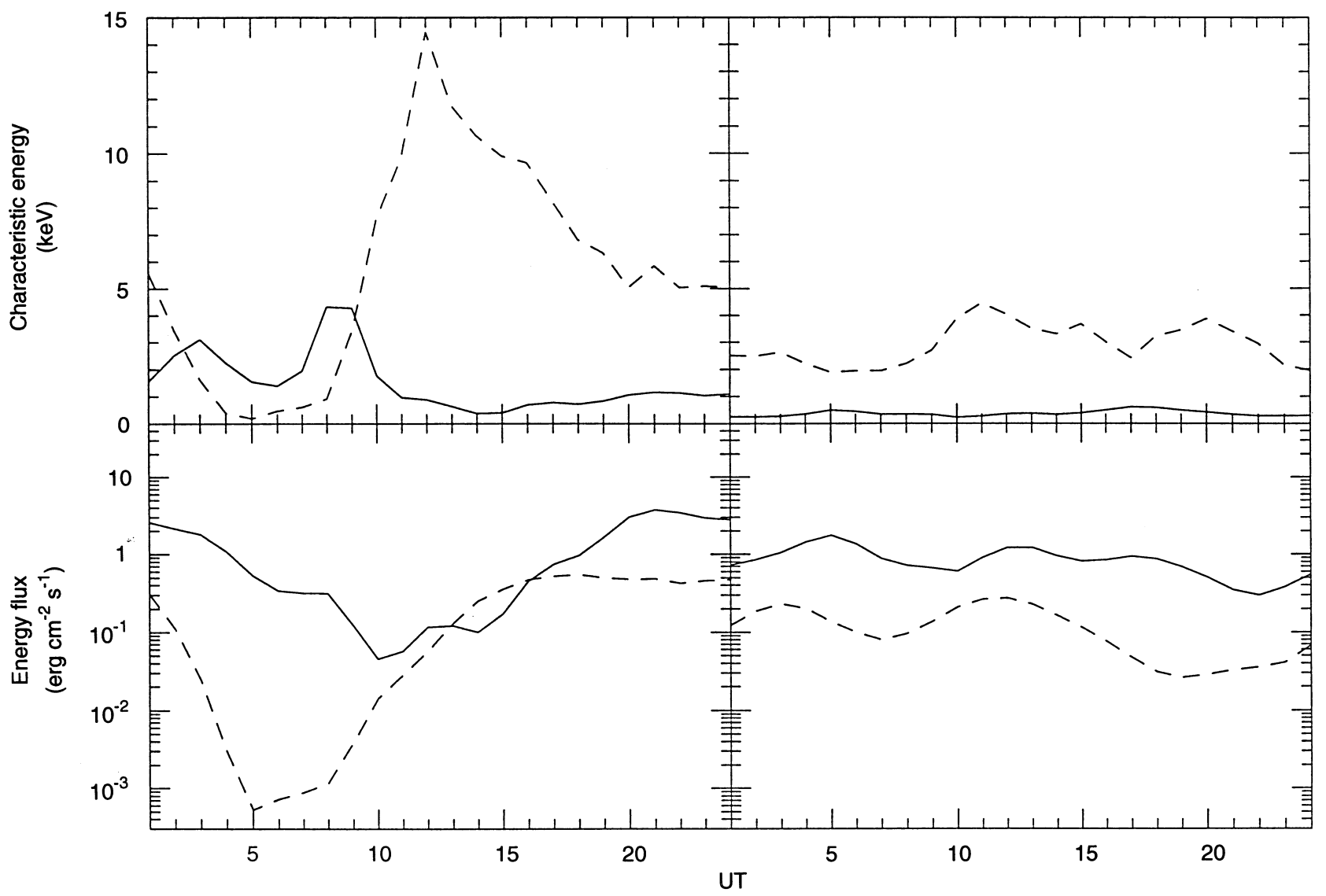

Fig. 8. The two lower panels show the integral energy flux of the electron precipitation (solid lines) and the ion precipitation (dashed lines) above EISCAT (Tromsø) (left) and ESR (right) for the same

geophysical conditions as during the Anderson et al. (1997) coordinated DMSP/EISCAT experiment $(A p=7)$. The two upper panels show the characteristic energies of these precipitations 

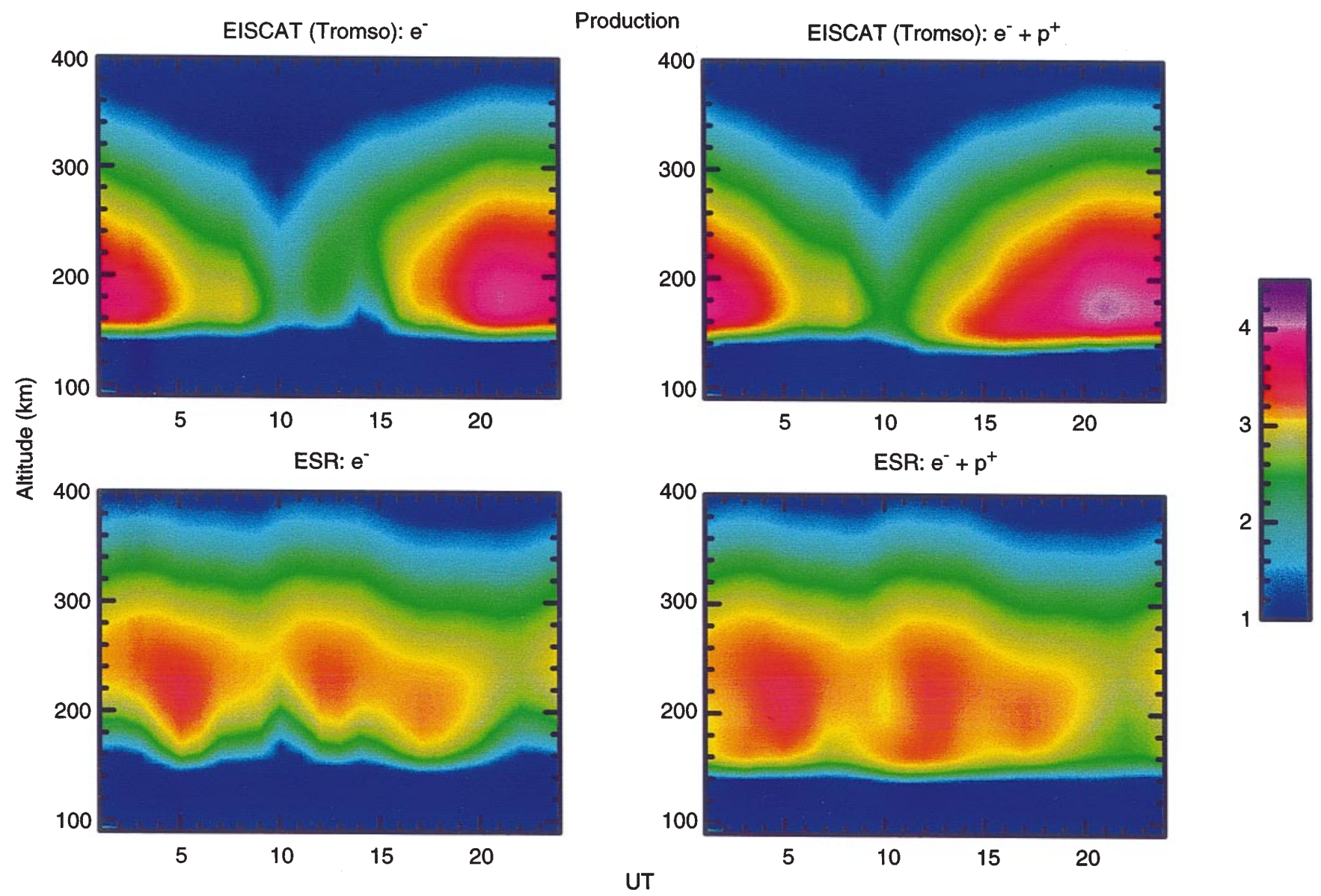

Fig. 9. The two left panels show the effect of the electron precipitation from the Hardy model above EISCAT (Tromsø) (top) and ESR (bottom) on the electron production, in electron $\cdot \mathrm{cm}^{-3} \cdot \mathrm{s}^{-1}$. The effect of coupled electron/proton precipitation is shown in the two right panels

high density area, and creates a maximum of density around $230 \mathrm{~km}$. During most of the day, the protons are responsible for the production below $160 \mathrm{~km}$. Over the whole day, the electrons contribute between $50 \%$ and $100 \%$ of the ionization at $160 \mathrm{~km}$ height. The effects are quite different above EISCAT (Tromsø) and ESR. At $300 \mathrm{~km}$, the electrons contribute for at least $80 \%$ of the production above EISCAT (Tromsø), and more than 95\% above ESR. Below $160 \mathrm{~km}$ (EISCAT Troms $\varnothing$ ) and $146 \mathrm{~km}$ (ESR) protons may have an influence equal to or larger than electrons on the electron production. When considering the densities, these altitudes are respectively $146 \mathrm{~km}$ and $137 \mathrm{~km}$.

\section{Conclusion}

A coupled electron/proton kinetic transport code has been developed. It has been successfully tested versus one satellite/radar experiment and another model. More tests have been performed on each part of this code and are described elsewhere (Galand et al., 1997; Lummerzheim and Lilensten, 1994). Of course, only one comparison with an experiment makes no proof of validity, and we are currently setting several spacecraft/ ESR/EISCAT experiments in order to further validate this model.
The study of pure proton precipitation has shown that protons and hydrogen atoms are less efficient in creating secondary production than the solar photons: the proto-electron efficiency, or the ratio of the production of secondary to proto-electrons, is less than $30 \%$.

Considering the first good results provided by the coupled code, we used as model inputs the ion and electron precipitation given by Hardy et al. $(1985,1989)$ to study theoretically the effect of a dual precipitation above EISCAT (Tromsø) and ESR. Our study shows that the proton precipitation can play a key role as a source of ionization. Below about $145 \mathrm{~km}$, it can even become the major source. Therefore the hydrogen component of the precipitations cannot be neglected in studies dealing with the high latitude ionosphere.

Acknowledgements. M.G. gratefully acknowledges the financial support of the Advanced Study Program and the High Altitude Observatory, at the National Center for Atmospheric Research (NCAR), which is sponsored by the National Science Foundation. Part of the computations presented here were performed at the Centre de Calcul Intensif de l'Observatoire de Grenoble. EISCAT is an international association supported by the research councils of Finland (SA), France (CNRS), the Federal Republic of Germany (MPG), Norway (NAVF), Sweden (NFR) and the United kingdom (SERC).

Topical Editor D. Alcaydé thanks a referee for his help in evaluating this paper. 


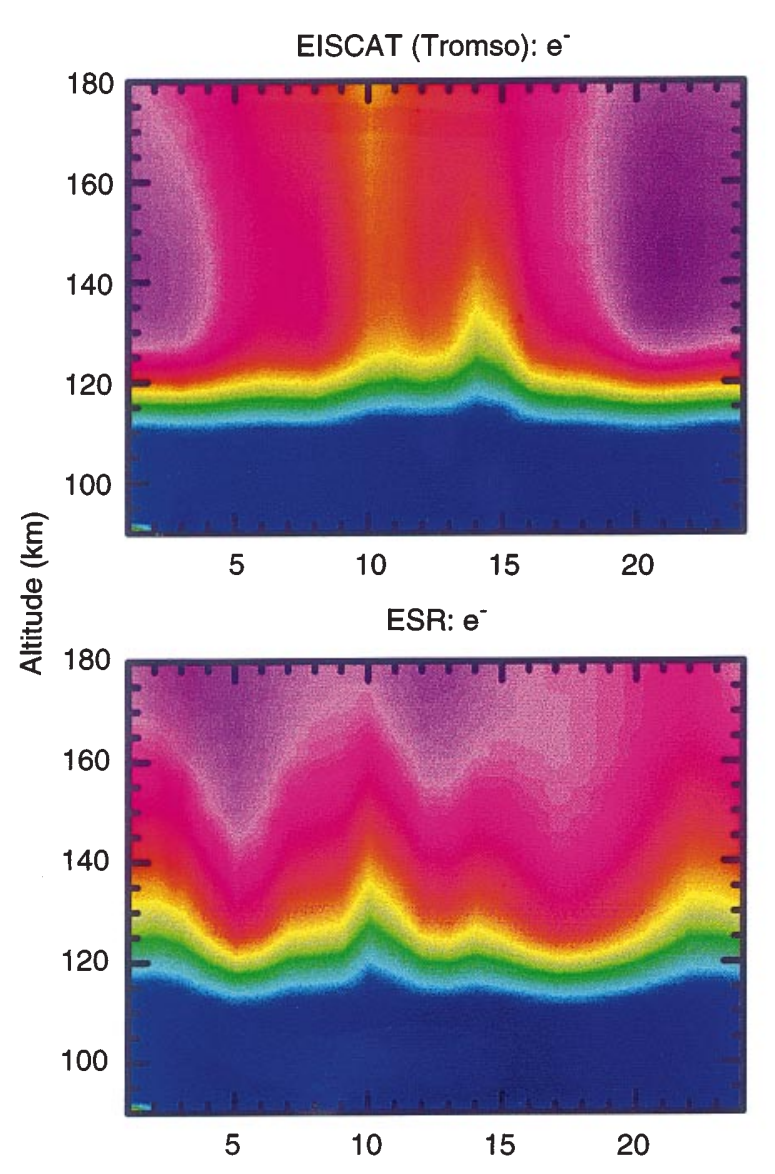

Density
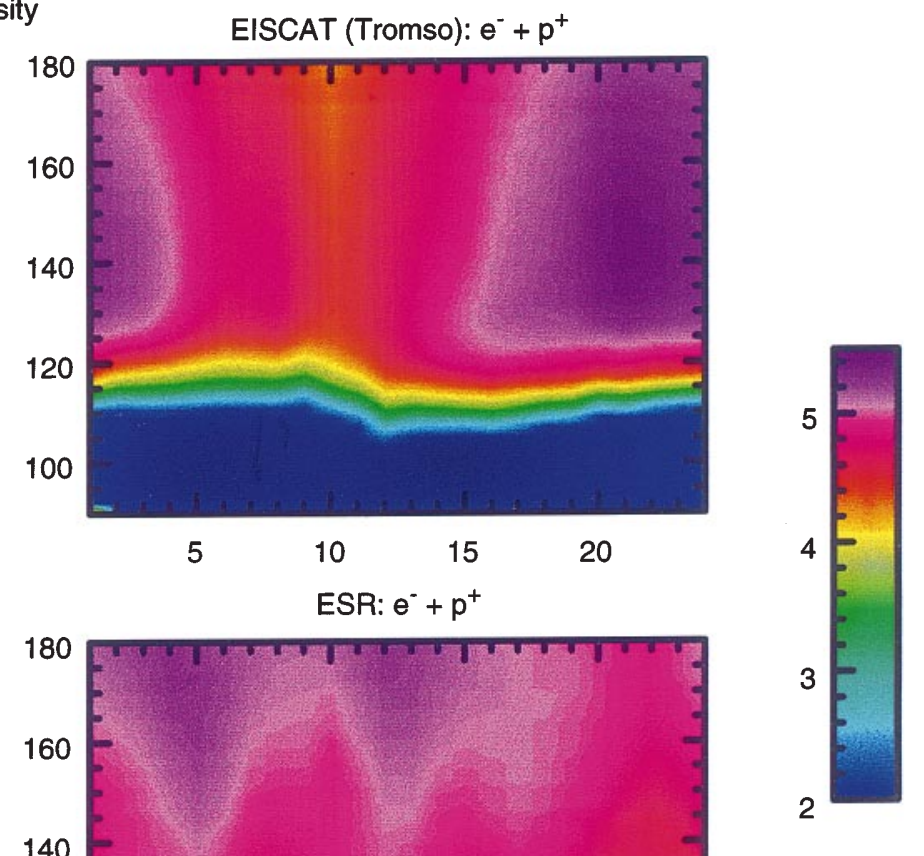

Fig. 10. Same as Fig. 9 for the electron density in electron $\cdot \mathrm{cm}^{-3}$

\section{References}

Anderson P. C., I. W. McCrea, D. J. Strickland, J. B. Blake, and M. D. Looper, Coordinated EISCAT/DMSP measurements of electron density and energetic electron precipitation, J. Geophys. Res., 102, 7421-7430, 1997.

Banks, P. M., C. R. Chappell, and A. F. Nagy, A new model for the interaction of auroral electrons with the atmosphere: spectral degradation, backscatter, optical emission and ionisation, $J$. Geophys. Res., 19, 1459-1470, 1974.

Basu, B., J. R. Jasperse, R. M. Robinson, R. R. Vondrak, and D. S. Evans, Linear transport theory of auroral proton precipitation: a comparison with observations, J. Geophys. Res., 92, 5920, 1987.

Basu, B., J. R. Jasperse, and N. J. Grossbard, A numerical solution of the coupled proton-H atom transport equations for the proton aurora, J. Geophys. Res., 95, 19 069, 1990.

Basu, B., J. R. Jasperse, D. J. Strickland, and R. E., Daniell, Transport-theoretic model for the electron-proton-hydrogen atom aurora, 1. Theory, J. Geophys. Res., 98, 21017 , 1993.

Berger M. J., S. M. Seltzer, and K. Maeda, Energy deposition by auroral electrons in the atmosphere, J. Atmos. Terr. Phys., 32, $1015,1970$.

Blelly, P-L, J. Lilensten, A. Robineau, J. Fontanari, and D. Alcaydé, Calibration of a numerical ionospheric model using EISCAT data: effect of the neutral atmosphere and the suprathermal electrons on the ionospheric plasma structure, Ann. Geophysicae, 14, 1375-1390, 1996.

Decker, D. T., B. V. Kozelov, B. Basu, J. R. Jasperse, and V. E. Ivanov, Collisional degradation of the proton-H atom fluxes in

the atmosphere: a comparison of theoretical techniques, $J$. Geophys. Res., 101, 26947-26960, 1996.

Edgar, B. C., W. T. Miles, and A. E. S. Green, Energy deposition of protons in molecular nitrogen and applications to proton auroral phenomena, J. Geophys. Res., 78, 6595, 1973.

Edgar, B. C., H. S. Porter, and A. E. S. Green, Proton energy deposition in molecular and atomic oxygen and applications to the polar cap, Planet. Space Sci., 23, 787, 1975.

Galand M., J. Lilensten, W. Kofman, and R. B. Sidje, Proton transport model in the ionosphere 1. Multistream approach of the transport equations, J. Geophys. Res., 102, 22 261-22 272, 1997.

Galand M., J. Lilensten, W. Kofman, and D. Lummerzheim, Proton transport model in the ionosphere 2. Influence of magnetic mirroring and collisions on angular redistribution in proton beam, Ann. Geophyicae, this issue, 1998.

Grün A. E., Lumineszenz-photometrische Messungen der Energieabsorption im Strhlungsfeld von Elektronenquellen: Eindimensionaler Fall in Luft, Z. Naturforschg., 12, 89, 1957.

Hardy, D. A., H. C. Yeh, L. K. Schmitt, T. L. Shumaker, M. S. Gussenhoven, A. Huber, F. J. Marshall, and J. Pantazis, Precipitating electron an ion detectors $(\mathrm{SSJ} / 4)$ on the block 5D/Flights 6-10 DMSP satellites: calibration and data presentation, Tech. Rep. AFGL-TR-84-0317, Air Force Geophys. Lab., Hanscom Air Force Base, Mass., 1984.

Hardy D. A., M. S. Gussenhoven, and E. Holeman, A statistical model of auroral electron precipitation., J. Geophys. Res., 90, A5, 4229-4248, 1985.

Hardy D. A., M. S. Gussenhoven, and D. Brautigam, A statistical model of auroral ion precipitation., J. Geophys. Res., 94, 370, 1989. 
Hedin A. E., Extension of the MSIS thermosphere model into the middle and lower atmosphere, J. Geophys. Res., 96, 1159-1172, 1991.

Jasperse, J. R., Boltzman-Fokker-Plank model for the electron distribution function in the Earth's atmosphere, Planet. Space Sci., 24, 33, 1976.

Jasperse, J. R., and D. J. Strickland, Approximate analytic solutions for the primary auroral electron flux and related quantities, Environmental research paper, Air Force Geophysics Lab., Space Physics Division, Massachusetts 01731, 1981.

Jasperse, J. R., and B. Basu, Transport theoretic solutions for auroral proton and $\mathrm{H}$ atom fluxes and related quantities, $J$. Geophys. Res., 87, 811, 1982.

Kozelov, B. V., and V. E. Ivanov, Monte Carlo calculations of proton-hydrogen atom transport in $\mathrm{N}_{2}$, Planet. Space Sci., 40, $1503,1992$.

Kozelov, B. V., Influence of the dipolar magnetic field on transport of proton-H atom fluxes in the atmosphere, Ann. Geophysicae, 11, 697, 1993.

Kozelov, B. V., and V. E. Ivanov, Effective energy loss per electronion pair in proton aurora, Ann. Geophysicae, 12, 1071, 1994.

Lanchester, B. S., J. R. Palmer, M. H. Rees, D. Lummerzheim, K. U. Kaila, and T. Turunen, Energy flux and characteristic energy of an elemental auroral structure, Geophys. Res. Lett., 21, 27892792, 1994

Lanchester, B. S., K. U. Kaila, and I. W. McCrea, Relationships between large horizontal electric fields and auroral arc elements, J. Geophys. Res., 101, 5075, 1996.

Lathuillere, C., P. L. Blelly, J. Lilensten, and P. Gaimard, Storm effects on the ion composition, accepted by Advanced and Space Research, 1997.

Lilensten, J., W. Kofman, J. Wisemberg, E. S. Oran, and C. R. DeVore, Ionization efficiency due to primary and secondary photoelectrons: a numerical model, Ann. Geophysicae, 7, 83-90, 1989.

Lilensten, J., P-L. Blelly, W. Kofman, and D. Alcaydé, Auroral ionospheric conductivities: a comparison between experiment and modeling, and theoretical f107 dependent model for EISCAT and ESR, Ann. Geophysicae, 14, 1297-1304, 1996.

Link R, S. Chakrabarti, G. R. Gladstone, and J. C. McConnell, an analysis of satellite observation of the OIEUV dayglow, $J$. Geophys. Res., 97, 14631, 1988.

Lummerzheim D., and J. Lilensten, Electron transport and energy degradation in the ionosphere: evaluation of the numerical solution, comparison with laboratory experiments and auroral observations, Ann. Geophysicae, 12, 1039-1051, 1994.

Lummerzheim D., M. H. Rees, and H. R. Anderson, Angular dependent transport of auroral electrons in the upper atmosphere, Planet. Space Sci., 37, 109-129, 1989.

Mantas, G. P., Theory of photoelectron thermalization and transport in the ionosphere, Planet. Space Sci., 23, 337-354, 1975.

McNeal, R. J., and J. H. Birely, Laboratory studies of collisions of energetic $\mathrm{H}^{+}$and hydrogen with atmospheric constituents, Rev. Geophys. Space Phys., 11, 633, 1973.
Nagy, A. F., and P. M. Banks, Photoelectron fluxes in the ionosphere, J. Geophys. Res., 75, 6260-6270, 1970.

Oran, E. S., V. B. Wickward, W. Kofman, and A. Newman, Auroral plasma lines: a first comparison of theory and experiment, $J$. Geophys. Res., 86, 199-205, 1981.

Rees, M. H., Auroral ionization and excitation by energetic electrons, Planet. Space Sci., 11, 1209-1218, 1963.

Rees, M. H., On the interaction of auroral protons with the Earth's atmosphere, Planet. Space Sci., 30, 463, 1982.

Richards, P. G., and D. G. Torr, The altitude variation of the ionospheric photoelectron flux: a comparison of theory and measurement, J. Geophys. Res., 90, 2877, 1985.

Richards, P. G., and D. G. Torr, Ratio of photoelectron to EUV ionization rate for aeronomic studies, J. Geophys. Res., 93, 4060-4066, 1988.

Senior, C., Solar and particle contributions to auroral heightintegrated conductivities form EISCAT data: a statistical study, Ann. Geophysicae, 9, 449-460, 1991.

Senior, C., J. R. Sharber, O. de la Beaujardiere, R. A. Heelis, D. S. Evans, J. D. Winningham, M. Sugiura and W. R. Hoegy, $E$ and $F$ region study of the evening sector auroral oval: a Chatanika/ Dynamics Explorer2/NOAA6 comparison, J. Geophys. Res., 92, 2477, 1987.

Sharp, R. D., R. G. Johnson, M. F. Shea, and G. B. Shook, Satellite measurements of precipitating protons in the auroral zone, $J$. Geophys. Res., 72, 227, 1967.

Sharp, R. D., D. L. Carr, and R. G. Johnson, Satellite observations of the average properties of auroral particle precipitations: latitudinal variations, J. Geophys. Res., 74, 4618, 1969.

Stamnes, K., Analytic approach to auroral electron transport and energy degradation, Planet. Space Sci., 28, 427-441, 1980.

Stamnes, K., On the two-stream approach to electron transport and thermalization, J. Geophys. Res., 86, 2405-2410, 1981.

Strickland, D. J., D. L. Book, T. P. Coffey, and J. A. Fedder, Transport equation technique for the deposition of auroral electrons, J. Geophys. Res., 81, 2755-2764, 1976.

Strickland D. J., J. R. Jasperse, and J. A. Whalen, Dependence of auroral FUV emissions on the incident electron spectrum and neutral atmosphere, J. Geophys. Res., 88, 8051, 1983.

Strickland D. J., R. R. Meier, J. H. Hecht, and A. B. Christensen, Deducing composition and incident electron spectra from ground based auroral opticla measurements: theory and model results, J. Geophys. Res., 94, 135274, 1989.

Strickland, D. J., R. E. Daniell, J. R. Jasperse, and B. Basu, Transport-theoretical model for the electron-proton-hydrogen atom aurora, 2. Model results, J. Geophys. Res., 98, 21 533, 1993.

Turunen T., T. Nygrén, and A. Huuskonen, Nocturnal high-latitude E region in winter during extremely quiet conditions, J. Atmos. Terr. Phys., 55, 783, 1994.

Vallance Jones A., Aurora, Reidel, Dordrecht, 1974.

Vegard, L., Emission spectra of night sky and aurora, Report of the Gassiot Committee, 82, The Physical Society London, 1948. 